\title{
Facilitating care of patients with HIV infection by hospital and primary care teams
}

\author{
Ann Smits, Simon Mansfield, Surinder Singh
}

\begin{abstract}
To complement the role of primary care teams working with patients with HIV disease and AIDS within greater London and to ease the load on the special hospital units a home support team was developed. It comprises six specialist nurses, a general practitioner trained medical officer, and a receptionist and is funded from regional and district sources and charities. A nurse is available for out of hours and emergency weekend calls, with support from the patient's general practitioner or the attached medical officer. During the first 18 months 249 patients were seen; the mean duration of care was five months. Nearly a third $(18 / 50,30 \%)$ of patients who were terminally ill died at home. The team's activities included practical nursing care, emotional support for carers and patients, and advice and guidance to primary care teams. Problems in providing care in patients' homes included issues relating to confidentiality and 24 hour cover.

With the increasing incidence of HIV infection the home support team may be a useful model for care of large numbers of patients with symptomatic HIV disease, especially in large urban areas.
\end{abstract}

\section{Introduction}

Of the various diverse and innovative strategies that have been designed and adopted to meet the needs of patients with HIV infection and AIDS, ${ }^{1-3}$ it is clear that most of the burden imposed on the health care services by HIV infection has been shouldered by hospital units. ${ }^{+}$This imbalance cannot be sustained, especially in areas with a high prevalence of infection such as London; here calls for a greater role for community care have been loudest. ${ }^{5}$ Unfortunately, the early responses of the primary care services served to highlight attitudinal deficiencies. ${ }^{6-11}$

Against this background St Mary's Hospital, which is in the North West Thames region, an area with the highest numbers of seropositive patients and patients with AIDS, developed the idea of a home support team to care for patients with HIV infection. Other specialised home support teams have been developed in London, ${ }^{12}$ and recently a Hospital at Home scheme in Peterborough with possible implications for care of patients with HIV has been described.'

We describe the establishment of the home support team over the first 18 months and report the preliminary results of its work.

\section{Home support team}

The home support team aims at providing practical and emotional support for patients with HIV infection, their carers, and health care workers. In essence, it bridges the gap that exists between primary and secondary care. Implicit in the proposal of a community team was a wish to redress the imbalance in the care of patients by acute hospital units. An important and easily underestimated role is to provide an influential role model for primary care teams. HIV infection and AIDS are new conditions with several associated fears, anxieties, and misconceptions. It is hoped that the home support team might help to encourage health care workers to be involved when otherwise they would not.

\section{Patients and methods}

The team consists of six sisters or charge nurses, a general practice trained medical officer, and receptionist staff. The final funding of the project comes from regional and district sources and charities. A nurse is available for out of hours calls and at weekends for emergencies only, with medical support from the patient's general practitioner or the attached medical officer.

The two main sources of referral to the team are from the hospital wards and the clinic (either the genitourinary clinic or the immunology clinic). All patients are positive for HIV antibody and are resident within Parkside District Health Authority or patients of this hospital and living within greater London. Once a referral has been recorded a member of the team assesses the patient, usually on the same day or within 24 hours if they are an inpatient.

The main reasons for referral are (table I):

TABLE I - Reason for referral to home support team

\begin{tabular}{lc}
\hline & No $(\%)$ \\
\hline Support and counselling & $164(66)$ \\
Social problems & $35(14)$ \\
Deterioration in physical or mental condition & $25(10)$ \\
Welfare rights advice & $12(5)$ \\
For general practitioner referral or liaison & $4(1 \cdot 6)$ \\
Not recorded & $9(3 \cdot 6)$ \\
\hline Total & 249
\end{tabular}

Medical and nursing - To ensure a smooth transition from hospital to home the team is asked to liaise with the patient's general practitioner and district nurses and to help mobilise community services. The team may also call on voluntary services and other agencies if required.

Psychoemotional-Continued support is often necessary after discharge. Sometimes a level of support over and above that which might be provided by a general practitioner is required, and specific counselling services may also be provided by the team.

Social-Referrals for social reasons inclide patients who are often homeless and thus have no primary care services. ${ }^{14}$ Problems with housing, social security payments, and employment are characteristic of this group. 


\section{Results}

In 18 months the team has provided services to 249 patients; table II shows the uptake of primary care services by them. The mean duration of care was 150 days, and an average of 36 contacts (including visits or telephone contacts) was made by a member of the team with a patient. Table III shows the reasons for call out of the team out of normal working hours; 286 telephone calls were received, and 136 visits were made out of hours.

TABLE II - Uptake of primary care services by 249 patients with HIV infection and AIDS

\begin{tabular}{lr}
\hline Type of service & No $(\%)$ \\
\hline General practitioners informed and involved & $197(79)$ \\
District nurses & $65(26)$ \\
Occupational therapists & $57(23)$ \\
Community social workers & $57(23)$ \\
Home helps & $32(13)$ \\
Buddies or other volunteers & $30(12)$ \\
\hline
\end{tabular}

TABLE III-Reason for patient initiated visits out of normal working hours

\begin{tabular}{ll}
\hline & No $(\%)$ \\
\hline Deterioration in condition requiring assessment & $54(40)$ \\
New symptom & $34(25)$ \\
Advice and reassurance (requiring more than telephone call) & $34(25)$ \\
Death of patient & $14(10)$ \\
\hline Total & 136 \\
\hline
\end{tabular}

Of all patients, 190 were alive at the end of 18 months, and $18(30 \%)$ of the 59 who died had done so at home.

\section{Discussion}

The policy of the home support team is active encouragement of patients to use the services of the primary care team. However, major difficulties have been highlighted in the use of primary care services by people with HIV infection ${ }^{6715}$ and in the relations between hospitals, patients, and the primary care services. The present system within hospitals for communicating with general practitioners and the overall reluctance of some units to communicate may marginalise the role of general practitioners to the point of undermining the care they give their patients. ${ }^{16}{ }^{17}$ Some general practitioners have negative attitudes to patients with HIV infection and AIDS. ${ }^{8.11}$ Patients themselves have genuine concerns about the ability of general practitioners to cater adequately for their needs. ${ }^{1819}$ One approach to such problems in palliative care has been to develop a hospital based support team that supplements the work of the hospital and primary care team. ${ }^{12}$

A clear dilemma for the support team occurs when patients do not want their diagnosis disclosed to their general practitioner. If their decision stands after a full explanation of the benefits and drawbacks of a disclosure this is respected. Such a decision results in a very limited role for the primary care team and certainly a lost educational opportunity.

That $79 \%$ of patients had informed and involved their general practitioner reflects how successful the team is in recruiting and working with primary care teams, and compares favourably with a value of $51 \%$ for patients with AIDS reported elsewhere. ${ }^{18}$ Inevitably, though reluctantly, the home support team occasionally assumed total care of a patient in the community. These instances were rare and usually of very short duration. Thirty per cent of deaths occurred at home, which is twice the figure quoted in the national surveillance data for patients with HIV infection (A R Kennedy et al, abstracts of fifth international conference on AIDS, Montreal, 1989) and equals that for deaths at home from all conditions. ${ }^{20}$ With AIDS care burdened by so many myths, misconceptions, and overt prejudice such encouraging results are testament to the commitment and effort by general practitioners and the home support team.

The objective of functioning alongside primary care teams and helping with discharge, maintenance, and follow up of patients in the community has meant the establishment of interdisciplinary groups, which not only permits discussion of patients and feedback but also affords an opportunity to inform, educate, and modify entrenched and often hardened attitudes to marginalised groups (drug misusers, gays, etc). A pivotal role for the team is in liaising with the nonstatutory sector, which can provide residential care, volunteer support, and hardship awards.

The availability of the team out of hours to patients and primary care teams is a key part of the service, which is used, especially at weekends, by patients who perceive themselves to have inadequate community support because of deputising general practitioners and district nurses and home helps who are unavailable.

Areas of care that are somewhat lacking in hospital and community are support and counselling. As the health service strives towards greater efficiency time consuming services with no easily measurable outcomes, such as counselling, are neglected in preference to task oriented work. Consequently, the team increasingly provides a support and counselling service as well as clinical care (see table I).

A separate audit within this project showed that two thirds of the working day of the nursing staff is taken up by face to face contact with patients (either within hospital or the home). An additional $15 \%$ is taken up by telephone calls, mostly to the patient but also to members of the primary care team. The overall function of these patient contacts is general nursing, supportive psychotherapy, and follow up.

Clearly the incidence of HIV infection will increase and therefore the need for community care will increase with it. ${ }^{21}$ Consequently, it is imperative that liaison between primary and secondary care services is flexible and responsive. The home support team is a model which aims at providing that service.

The average length of stay at this hospital for a person with AIDS fell by more than $70 \%$ from 1987 to 1988. Though we recognise that the reasons for this must be multifactorial, the influence of the home support team should not be underestimated. This initiative may be appropriate for highly urbanised areas in facilitating care of patients with HIV disease in the community.

We thank Anthony Pinching and Tony Levy for facilitating this project, Help the Hospices for some of the initial funding, and Paula Duffin and Ann Craig for their secretarial help.

1 Bould M, Peacock G. AIDS: models of care. London: King's Fund, 1989. 2 Robertson JR, Skidmore CA. Drug misuse strategies and AIDS prevention. Lancet 1988;i:422.

Stotter A. A different slant on surgery and HIV. Br Med J 1989;298:536

Adler MW. Care for patients with HIV infection and AIDS. Br Med 1987;295:27-30.

5 Cunningham D, Griffiths SF. AIDS: counting the cost. Br. Med $\mathcal{f}$ 1987;295: 921-2.

6 King MB. AIDS and the general practitioner: psychosocial issues. Health Trends 1987;19:1-3.

7 Searle ES. Knowledge, attitudes and behaviour of health professionals in relation to AIDS. Lancet 1987;i:26-8.

8 Milne RIC, Keen SM. Are general practitioners ready to prevent the spread of HIV? BrMed F 1988;296:533-5.

9 Anderson P, Mayon-White R. General practitioners and management of infection with HIV. Br Med f 1988;296:535-7.

10 Boyton R, Scambler G. Survey of general practitioners' attitudes to AIDS in the North West Thames and East Anglian regions. Br Med 7 1988;296: 538-40.

11 Sibbald B, Freeling P. AIDS and the future general practitioner. $\mathcal{F}$ R Coll (jen Pract 1988;38:500-2. 
12 Bates 'T, Hov AM, Clarke DG, Laird PP. The St Thomas' hospital terminal care support team. A new concept of hospice care. Lancet 1981;1:1201-3.

13 Anand JK, Pryor GA Morgan RTr. Hospital at home. Health Tromds 1989;21:46-7.

It Anonymous. Homelessness (E ditoriall. Lancet 1989;ii:778-9.

15 Hodgkin P. HIV infection: the challenge to general practitioners. Br Med 1988:296:5.

16 Harding J. Study of discharge communications from hospital doctors to an inner London general practice. $\mathcal{I}$ R Coll (ien Pract 1987;37:494-5.

17 Neville RG. Notifying general practitioners about deaths in hospital: an audit. fR Coll Gen P'ract 1987;37:496-7.
18 Mansfield SJ, Singh S. The general practitioner and human immunodeficiency virus infection: an insight into patients' attitudes. $7 \mathrm{R}$ Coll (jem Proct 1989:39:104-5.

19 King MB. AIDS and the general practitioner: views of patients with HIV infection and AIDS. Br Med F 1988:297:182-4.

20 Office of Population Census and Survevs. Mortality statistics. Series DHI No 20. London: HMSO, 1987.

21 Cox D. Short-term prediction of HIV infection and AIDS in England and Wales. London: HMSO, 1988.

(Accepted 17 November 1989
Susan J Smith

There is a long tradition in Britain of using housing interventions to promote public health, beginning with the Public Health Act of 1848 and the Housing Acts of the late nineteenth century, which were all preoccupied with disease control. Although the housing functions of the Ministry of Health were transferred to the Ministry of Housing and Local Government in 1951, the expansion of the public rented sector-a cornerstone of the welfare state-allowed local authorities routinely to shelter those whose market opportunities were undermined by poor health. By the time the Department of the Environment assumed ministerial responsibility for housing in 1970 the procedures for incorporating medical priority into housing allocations were well established. ${ }^{12}$ There is, nevertheless, a second housing and health tradition in Britain, grounded in the use of residential institutions to contain and control certain medical problems - to isolate infectious disease, manage psychiatric disorder, and service frailty or disability. ${ }^{34}$ These contrasting approaches to accommodating sick people-rooted, respectively, in the principle of disease prevention or health promotion and in the philosophy of containment and control-are a continuing source of tension within housing policy and practice.

Although deinstitutionalisation has gathered momentum since the 1950 s, supposedly implemented hand in hand with the development of community care, the procedure has no explicit housing component, and no extra general needs, state subsidised housing was ever earmarked for it. On the contrary, since the end of the 1960s and especially since 1980 public housing - the key to adequate shelter for those whose health state inhibits their labour market opportunities - has been declining in significance. The council stock has diminished in size and quality and is becoming a residual sector, accommodating low income populations in the least desirable dwellings and locations. One well documented consequence is that the otherwise welcome demise of overinstitutionalisation - the undermining of a "control and containment" policy for dealing with disease - has contributed to an unprecedented increase in homelessness ${ }^{6}$ and to the changing health profile of homeless people. ${ }^{278} \mathrm{~A}$ second consequence has received much less attention.

As local authorities have responded to the housing implications of community care, the use and effectiveness of mainstream housing policy to meet general medical needs (mobilising the philosophy of housing as health promotion) has been eclipsed by the development of "special" housing initiatives, which are targeted towards the fairly narrow range of medical needs experienced by those "elderly," "mentally handicapped," "mentally ill" or "physically disabled" populations who had once been institutionalised. Even then, only a small proportion of these institutionally defined special populations can be accommodated, ${ }^{89}$ and notwithstanding the benefits for some of these people, special housing initiatives can be criticised as both segregative and stigmatising." The "special needs" approach has, in short, begun to drift away from the ideal of housing as health promotion and towards the model of housing as containment and control it was designed to overcome.

It is in this context-at the height of the special needs era-that the AIDS and housing movement has gathered momentum. A national AIDS and housing project was set up in 1985 as a joint venture of the National Federation of Housing Associations and the Special Needs Advisory Service, with initial backing from a charitable trust, in response to the failure of housing institutions to provide adequate accommodation for people infected with HIV. ${ }^{12}$ Activists immediately faced the dilemma that, on the one hand, claims to special dispensation could reinforce the stigma already attached to AIDS, but that on the other hand, in a rapidly restructuring welfare state, special designation is the most effective way to secure housing resources on the grounds of medical need. The AIDS and housing movement chose, with others, to campaign to extend the scope of special designation beyond groups traditionally associated with the process of deinstitutionalisation to include others (black people, single homeless people, and one parent families as well as people with HIV) who also experience discrimination and disadvantage in the housing system. People infected with HIV therefore laid claim to special housing resources both on the grounds of medical need, and in the face of discrimination through mainstream housing policy.

Building on this claim, a range of AIDS and housing guidelines have now been developed: the Housing Corporation has issued circulars, some local authorities and London boroughs have drawn up policies, and working groups associated with charitable and voluntary organisations have published reports. ${ }^{1131+}$ Notwithstanding their origins in the special needs tradition, these recommendations promise to shift the balance of the special housing debate away from its implicit preoccupation with containment and control towards the more ambitious ideals of disease prevention and health promotion.

Firstly, the new guidelines identify a fixed address rather than a particular form of dwelling as the centrepiece of health care policy for patients positive for HIV. Research continues to expose the inadequacy of primary health care available to homeless people, and the problem is compounded for people with AIDS, ${ }^{16} 17$ who are particularly vulnerable to homelessness: young single people have low priority in most local authority waiting lists; and HIV infection is a barrier to obtaining a mortgage. ${ }^{18}$ The expansion of the private rented sector seems likely to occur up market; down market tenants face only the prospects of short 